\title{
Applying Generalized Pareto Curves to Inequality Analysis
}

Author(s): Thomas Blanchet, Bertrand Garbinti, Jonathan Goupille-Lebret and Clara Martínez-Toledano

Source: AEA Papers and Proceedings, MAY 2018, Vol. 108, PAPERS AND PROCEEDINGS OF THE One Hundred Thirtieth Annual Meeting OF THE AMERICAN ECONOMIC ASSOCIATION (MAY 2018), pp. 114-118

Published by: American Economic Association

Stable URL: https://www.jstor.org/stable/10.2307/26452716

JSTOR is a not-for-profit service that helps scholars, researchers, and students discover, use, and build upon a wide range of content in a trusted digital archive. We use information technology and tools to increase productivity and facilitate new forms of scholarship. For more information about JSTOR, please contact support@jstor.org.

Your use of the JSTOR archive indicates your acceptance of the Terms \& Conditions of Use, available at https://about.jstor.org/terms 


\title{
Applying Generalized Pareto Curves to Inequality Analysis
}

\author{
By Thomas Blanchet, Bertrand Garbinti, Jonathan Goupille-Lebret, \\ and Clara Martínez-Toledano*
}

Ever since Pareto's (1896) work, it has been known that the top tail of income and wealth distributions is well approximated by a power law. As a first order approximation, this regularity has proved to be remarkably consistent over time and between countries. In particular, economists have used it in empirical work to exploit tabulated fiscal data (Kuznets and Jenks 1953; Atkinson and Harrison 1978; Piketty and Saez 2003; Piketty 2003).

There are, however, some deviations from this idealized model. This is true both at the bottom and at the top of the distribution. By taking these deviations into account, we can improve both the quality of empirical work and our understanding of how income and wealth concentrations change over time and between countries. This article illustrates that point. Real distributions of income and wealth may be seen as having Pareto coefficients that depend on the rank $p \in[0,1]$ in the distribution. By letting these coefficients vary, we allow for more flexibility and precision while still keeping the Pareto model as a baseline. We first show how this framework can be used to better estimate distributions from data available in tabulated format, a common issue with administrative tax data. We then describe some stylized facts about these coefficients for income and wealth distributions.

\footnotetext{
* Blanchet: Paris School of Economics, 48 boulevard Jourdan, 75014 Paris (email: thomas.blanchet@wid. world); Garbinti: Banque de France, 31 rue Croix des Petits Champs, 750001 Paris, and CREST (email: bertrand. garbinti@banque-france.fr); Goupille-Lebret: Paris School of Economics, 48 boulevard Jourdan, 75014 Paris, and INSEAD (email: jonathan.goupille@ens.fr); MartínezToledano: Paris School of Economics, 48 boulevard Jourdan, 75014 Paris (email: c.martinez-toledano@psemail. eu). We are thankful to Thomas Piketty and Emmanuel Saez for fruitful discussions and helpful comments. This paper presents the authors' views and should not be interpreted as reflecting those of their institutions.

${ }^{\dagger}$ Go to https://doi.org/10.1257/pandp.20181075 to visit the article page for additional materials and author disclosure statement $(\mathrm{s})$.
}

\section{Generalized Pareto Curves: Theory and Applications}

\section{A. Theory}

A variable is said to follow a Pareto distribution if its cumulative distribution function is written, $F(x)=1-(\mu / x)^{\alpha}$, for $x>\mu>0$. A property that characterizes the Pareto distribution, sometimes known as van der Wijk's law, is that the average income of individuals above any income threshold, divided by that threshold, is constant and equal to the inverted Pareto coefficient $b=\alpha /(\alpha-1)$. The share of the top $100 \times(1-p) \%$ (for instance, the share of the top 10 percent, which corresponds to $p=0.9$ ) is then an increasing function of $b$, equal to $(1-p)^{1 / b}$, so that $b$ may be viewed as a concentration indicator.

In practice, the Pareto model never holds exactly, not even at the top. Indeed, it imposes the tight constraint that inequality is the same within all top income groups: the full distribution is the same (up to a scaling factor) as the distribution within the top 10 percent, 1 percent, or 0.1 percent, which is not necessarily the case. This property is occasionally referred to as the "fractal" nature of inequality. To relax this constraint, Blanchet, Fournier, and Piketty (2017) formalize a "local" concept of Pareto coefficient $b(p)$ defined as the ratio between the average income or wealth above rank $p$, and the $p$ th quantile. It can be written:

$$
b(p)=\frac{E[X \mid X>Q(p)]}{Q(p)},
$$

where $Q$ is the quantile function. For a strict Pareto law, $b(p)$ is constant, but otherwise, it will vary. We call the curve $p \mapsto b(p)$ the "generalized Pareto curve." It characterizes the distribution (up to a constant) in a manner that emphasizes the way inequality evolves when we look further up the distribution. At the limit, 
$b(p)=1$ defines a situation where all individuals above rank $p$ have the same income or wealth, so that there is no inequality above $p$. A higher $b(p)$ corresponds to higher levels of inequality.

Hence, a nonconstant $b(p)$ indicates deviations from the "fractal" nature of inequality: when it is increasing with $p$, it means that income is getting more concentrated the further we move up in the income distribution, so that, say, the share of the top 0.1 percent within the top 1 percent is larger than the share of the top 1 percent within the top 10 percent.

\section{B. Applications}

For logistical and/or privacy reasons, administrative tax data are often not available as microdata but as tabulations. These tabulations take the form of several thresholds for which we have both the number of individuals above the threshold, and the income owned by these individuals. Hence, it is possible to calculate $b(p)$ for a finite number of values of $p$. Earlier work exploiting such data would then often calculate income thresholds and income shares of interest under the assumption that $b(p)$ is constant within tabulation thresholds (e.g., Piketty and Saez 2003; Piketty 2003).

A new and better solution relies on generalized Pareto interpolation, as developed by Blanchet, Fournier, and Piketty (2017). It has already been applied through numerous recent works related to the DINA project.

Instead of assuming a piecewise constant Pareto curve, which leads to highly irregular and potentially inconsistent distributions of income or wealth, the generalized Pareto interpolation method uses an appropriately constrained spline approximation of a simple transformation $b(p)$ to find the "most regular" Pareto curve that satisfies the information in the tabulated data.

A simple example can show how generalized Pareto interpolation can improve the precision of estimates in empirical inequality research. Take countries, like France, Spain, and the United States, for which we have detailed, quasi-exhaustive microdata. We use these data to create tabulations with arbitrary thresholds, and then estimate shares with a different threshold. When predicting the top 10 percent share based on the top 30 percent and 1 percent, both methods work quite well but the new one is better, as Figure 1
Panel A

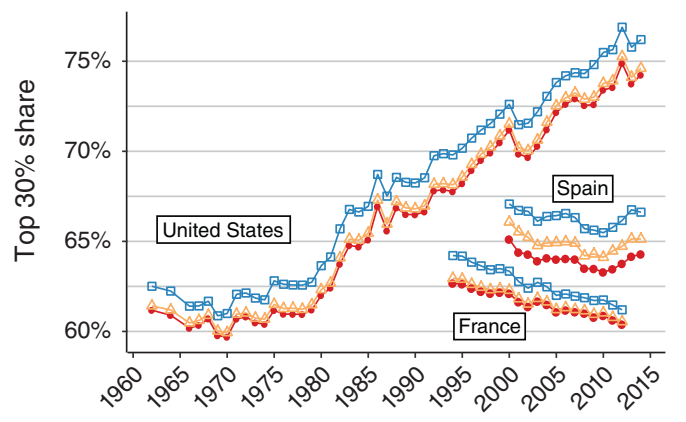

Panel B

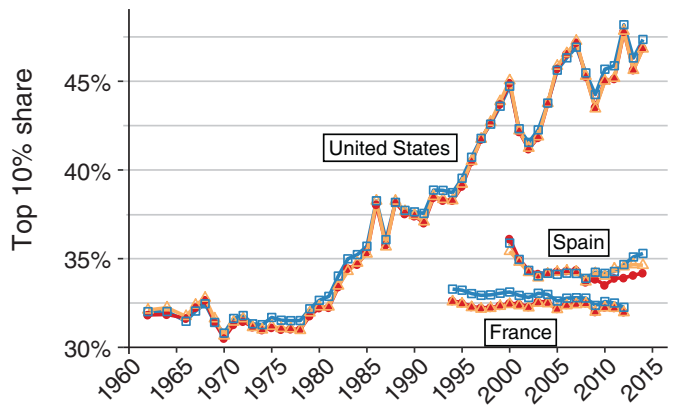

Panel C

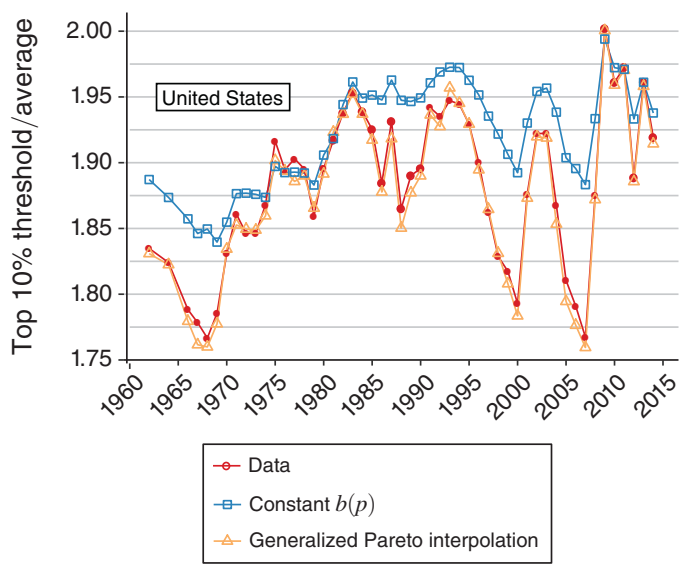

Figure 1. Comparison of Interpolation Methods

Notes: Fiscal income. Top 10 percent estimated based on the top 30 percent and the top 1 percent. Top 30 percent estimated from the top 50 percent and 10 percent.

Sources: France: Garbinti, Goupille-Lebret and Piketty (forthcoming); Spain: Martínez-Toledano (2017); United States: Piketty, Saez, and Zucman (2018).

shows. The results are even more pronounced if we use a lower point in the distribution, like the top 30 percent. Blanchet, Fournier, and Piketty 
(2017) compare the method using much more data and show that it performs substantially better than all the other methods currently used in the literature.

Surveys can also be a useful point of comparison. Take a large (50 million) sample representing the French income distribution. We can estimate by a Monte-Carlo approach the typical error of the estimate of the top 10 percent income share using large random subsamples of size 50,000. The average error on the top 10 percent income share is 0.34 percentage points, about three times as large as the average error on the top 10 percent share in Figure 1. The difference would be even bigger for smaller top income groups. This points to the importance of using administrative data for analyzing the top of the distribution, even when they take the form of tabulations.

The generalized Pareto interpolation can be extended in several directions: in particular, it is possible to adapt it to situations in which only thresholds or only shares are known. Because it always leads to a well-defined probability distribution, it is also easier to use generalized Pareto interpolation in conjunction with other statistical methods.

\section{Stylized Facts about Pareto Curves}

What may Pareto coefficients bring to inequality analysis? First, we show that studying jointly the evolution of Pareto coefficients and top shares can improve the understanding of inequality dynamics. Second, we present how Pareto curves may help to better analyze wealth and income concentration along the distribution.

\section{A. Analyzing Top Income Shares using Pareto and Gamma Coefficients}

In equation (1), we write the top 10 percent income share as the product of three elements: the share of the population in the top 10 percent $(0.1)$, the top 10 percent Pareto coefficient $b(p 90)$, and the $\gamma$ coefficient $\gamma(p 90)$, which is the ratio of the top 10 percent income threshold over the average income of the overall population:

(2) Top $10 \%$ share $=0.1 \cdot b(p 90) \cdot \gamma(p 90)$.
This simple decomposition allows to disentangle the variations of top 10 percent income shares over time into two different dynamics. Changes in Pareto coefficients $b(p)$ reflect a change in income concentration within the top 10 percent. These changes have to be explained by factors specific to the very top of the distribution (superstars effect, rent extraction, etc.). In contrast, changes in $\gamma$ coefficients denote a differential evolution between the top 10 percent income threshold and the average income. These changes have to be explained by factors playing on inequality within the bottom 90 percent (race between skill and education, minimum wage, job polarization, etc.). Figure 2 reports the evolution of top 10 percent income shares (panel A), and the evolution of top 10 percent Pareto and $\gamma$ coefficients (panel B) for France and the United States over the period 1965-2014. Panel A shows that French and United States top 10 percent income shares were similar in level and declining over the period 1965-1975. In the United States, starting from the mid-1970s, the top 10 percent income share stopped declining and rose continuously from 34 to 47 percent in 2014. In contrast, in France, the top 10 percent income share continued to decrease up to the early 1980s and then raised at a much more modest pace from 29 to 33 percent in 2014.

Panel B allows to better understand the different dynamics in each country. In the United States, since the mid-1980s, the income of all the top 10 percent richest individuals increased more rapidly than the average income (both Pareto and $\gamma$ coefficients increased). However, the rise has been much more pronounced for the very top incomes (steep increase of the Pareto coefficients), leading to an increasing income concentration within the top 10 percent. In France, the moderate increase of the top 10 percent income share since the mid-1980s was the result of two antagonistic forces. On one hand, the income of the poorest individuals in the top 10 percent increased at a slower pace than the average income ( $\gamma$ coefficient decreased). On the other hand, the income of the richest individuals in the top 10 percent increased much more rapidly than both the average income and income from the bottom part of the top 10 percent (Pareto coefficient increased). The conjunction of these two factors led to a polarization of the top 10 percent income group in France. 


\section{Panel A}

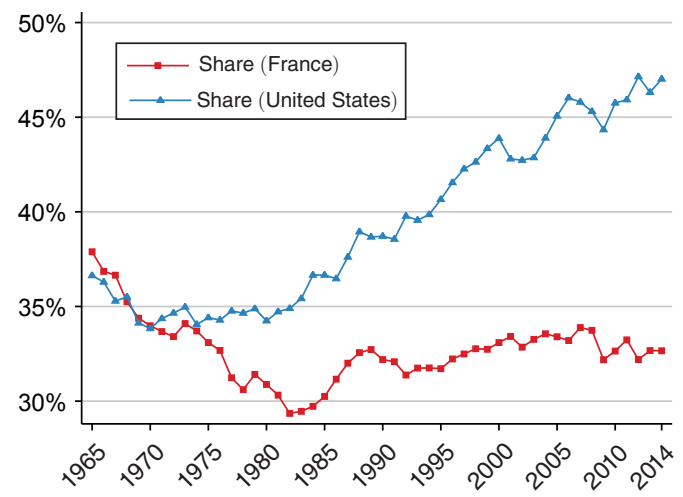

Panel B

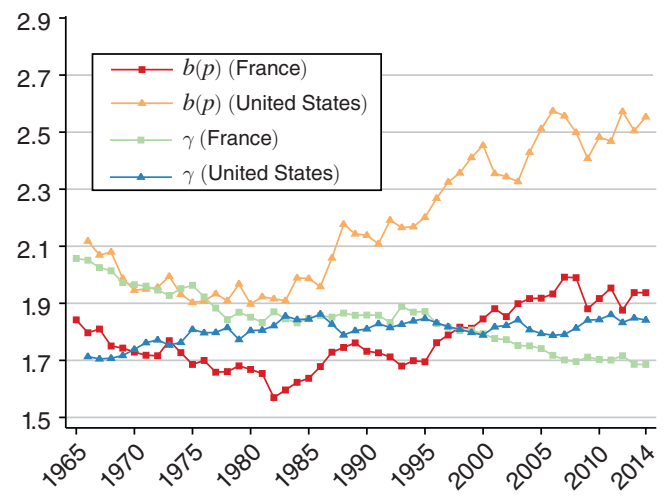

Figure 2. Evolution of Top 10 Percent Share, Pareto and Gamma CoEfFicients For the United STATES AND FRANCE, 1965-2014

Notes: Pretax national income (before taxes and transfers, except pensions and unemployment insurance). Equal-splitadult series.

Sources: United States: Piketty, Saez, and Zucman (2018); France: Garbinti, Goupille-Lebret, and Piketty (forthcoming).

\section{B. The Changing Slope of Pareto Curves}

Figure 3 presents the evolution of the Pareto coefficients $b(p)$ for the upper part of the distribution of wealth and pretax income.

Panel A shows that income concentration first decreases with $p$. The definition of $b(p)$ makes this decreasing part easy to interpret: the income of the poorest is very small relative to the average income of people richer than them. However, as we move up in the distribution, individuals' incomes start to represent a larger fraction of the
Panel A

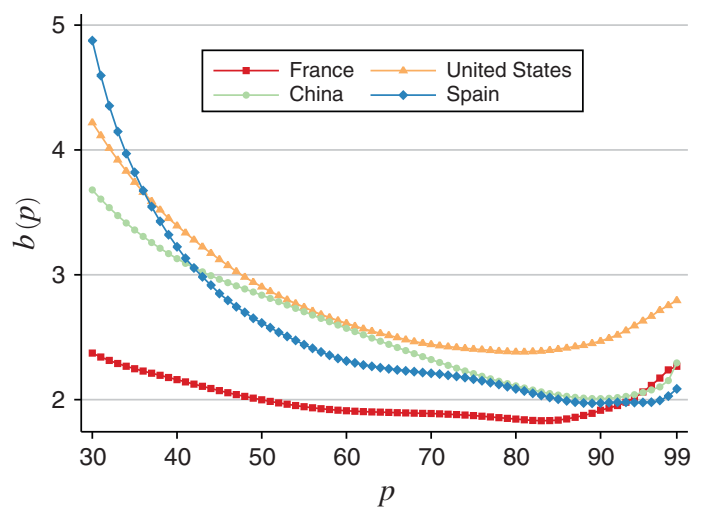

Panel B

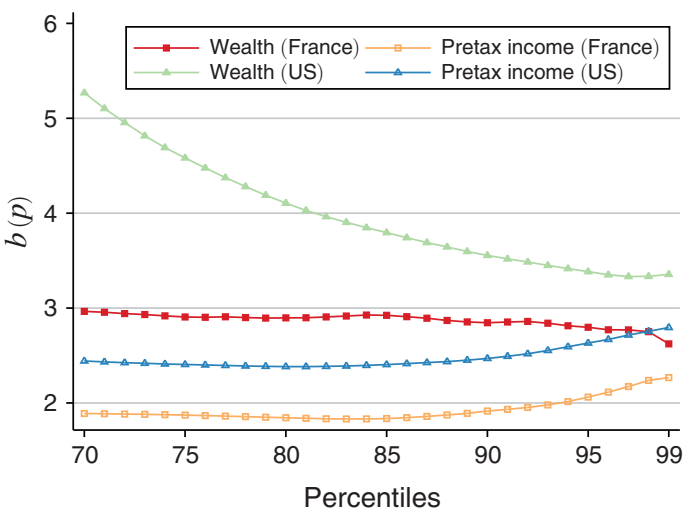

Figure 3. Pareto Coefficients for the Wealth and Pretax-Income Distributions, France and the United STATES, 2000-2014

Notes: Pareto coefficients averaged over the period 2000 2014. Pretax national income (before taxes and transfers, except pensions and unemployment insurance). Equal-splitadult series for wealth and pretax national income.

Sources: United States: Piketty, Saez, and Zucman (2018) and Saez and Zucman (2016); France: Garbinti, GoupilleLebret, and Piketty (2016, forthcoming); Spain: MartínezToledano (2017), China: Piketty, Yang, and Zucman (2017).

average income above them. Indeed, the average income above the poorest individuals is driven by high income held by the richest individuals. The slopes of $b(p)$ change around percentiles $p 80-p 90$ and then rise until the top of the distribution, which shows that within the top income earners there is also an important intragroup inequality due to the very top earners for whom income, and particularly capital income, is highly concentrated. Within the top 10 percent earners, income concentration is rather 
comparable between France, Spain, and China, while it is much larger in the United States. Panel B offers a comparison between wealth and income concentration for France and the United States. While income concentration increases at the top, wealth concentration is still decreasing until a fairly stable part. It reflects the fact that the different top wealth groups face similar levels of wealth concentration. In other words, inequality between the middle class on one hand and the wealthy on the other hand is more pronounced than inequality within the wealthy. It is also striking to notice that the large gap between income and wealth concentration dramatically narrows as we go higher in the distribution: very top incomes mainly consist of capital income whose level of concentration is close to that of wealth.

\section{Conclusion}

In this paper, we have explained and shown the usefulness of generalized Pareto curves to characterize, visualize, and estimate distributions of income or wealth. We have also presented the interest of interpreting the inverted Pareto coefficients. We hope the interpolation method presented here will help future researchers to improve our understanding of the dynamics of inequality.

\section{REFERENCES}

Atkinson, Anthony Barnes, Allan James Harrison. 1978. Distribution of Personal Wealth in Britain. New York: Cambridge University Press.

Blanchett, Thomas, Juliette Fournier, and Thomas Piketty. 2017. "Generalized Pareto Curves: Theory and Application." World Wealth and Income Database Working Paper 2017/3.

Garbinti, Bertrand, Jonathan Goupille-Lebret, and Thomas Piketty. Forthcoming. "Income Inequality in France, 1900-2014: Evidence from Distributional National Accounts (DINA)." Journal of Public Economics.

Garbinti, Bertrand, Jonathan Goupille-Lebret, and Thomas Piketty. 2016. "Accounting for Wealth Inequality Dynamics: Methods, Estimates and Simulations for France (1800-2014)." World Wealth and Income Distribution 2016/5.

Kuznets, Simon, and Elizabeth Jenks. 1953. "Shares of Upper Income Groups in Savings." In Shares of Upper Income Groups in Income and Savings, edited by Simon Kuznets and Elizabeth Jenks, 171-218. Chicago: National Bureau of Economic Research.

Martínez-Toledano, Clara. 2017. "Housing Bubbles, Offshore Assets and Wealth Inequality in Spain." World Wealth and Income Database Working Paper 2017/19.

Pareto, Vilfredo. 1896. Ecrits sur la courbe de la repartition de la richesse. Paris: Librairie Droz.

Piketty, Thomas. 2003. "Income Inequality in France, 1901-1998." Journal of Political Economy 111 (5): 1004-42.

Piketty, Thomas, and Emmanuel Saez. 2003. "Income Inequality in the United States, 1913-1998." Quarterly Journal of Economics 118 (1): 1-39.

Piketty, Thomas, and Emmanuel Saez, and Gabriel Zucman. 2018. "Distributional National Accounts: Methods and Estimates for the United States." Quarterly Journal of Economics. http://doi.org/10/1093.qje/qjx043.

Piketty, Thomas, Li Yang, and Gabriel Zucman. 2017. "Capital Accumulation, Private Property and Rising Inequality in China, 1978-2015." World Wealth and Income Distribution Working Paper 2017/6.

Saez, Emmanuel, and Gabriel Zucman. 2016. "Wealth Inequality in the United States since 1913: Evidence from Capitalized Income Tax Data." Quarterly Journal of Economics 131 (2): 519-78. 